\title{
Challenges and Strategies for Teachers and Learners of English as a Second Language: The Case of an Urban Primary School in Kenya
}

\author{
Jaswinder K. Dhillon $^{1} \&$ Jenestar Wanjiru ${ }^{1}$ \\ ${ }^{1}$ University of Wolverhampton, UK \\ Correspondence: Jaswinder K. Dhillon, School for Education Futures, University of Wolverhampton, Gorway \\ Road, Walsall, WS1 3BD, UK. E-mail: j.k.dhillon@wlv.ac.uk
}

Received: January 19, 2013 Accepted: February 16, 2013 Online Published: March 25, 2013

doi:10.5539/ijel.v3n2p14

URL: http://dx.doi.org/10.5539/ijel.v3n2p14

\begin{abstract}
With over 40 spoken tongues in Kenya, English serves as a language of instruction in schools and is taught from the onset of schooling, making the language a significant factor in academic achievement and subsequent social mobility. This article draws on a case study conducted in an urban multilingual primary school in Kenya and focuses on the challenges and strategies for teaching and learning English as a second language (ESL) in primary schools. The findings are based on evidence gathered from teachers, through questionnaires and semi-structured interviews, and from pupils, through learner diaries. The data show a strategic approach to teaching and learning English and reveal the tremendous effort invested by teachers and learners in grappling with the challenges of learning English in the context of an unresolved national language policy, interference from regional linguistic heritage languages and an examination-oriented education system. The strategies deployed by teachers to address these challenges include varied instructional approaches and creating a warm classroom climate to provide a non-threatening environment for learning and language acquisition. Data from pupils shows that group based interactions with their peers and individual reinforcement strategies, such as keeping vocabulary notebooks, are the most common learner strategies. The study shows how school-based research can give teachers and learners a voice in the development of successful language teaching and learning strategies for complex and challenging multilingual environments.
\end{abstract}

Key words: ESL, multilingualism, primary schools, teaching strategies, learner strategies, Kenya

\section{Introduction}

Learning a second language (L2) in multilingual environments can be more challenging than language learning in other contexts for a variety of reasons. In multilingual settings established patterns of communication may lead to the foreign tongue (English) being seen as an 'intruder' in the already established interaction system, especially amongst children. Literacy practices may appear complex due to unequal relationships between different languages (Asfaha \& Kroon, 2011) and contextual compromise in standard language use (Pitt, 2005) leading to adaptation and mixing of languages. Clegg and Afitska (2011) show how a lack of fluency in a common language leads to 'creative bilingual practices' in order to enable communication between teachers and learners in African classrooms.

Gorman (1968) assessed the importance of proficiency in English for social mobility and the role of educational provision in attaining proficiency in English in a multilingual environment. Gorman used the term 'bilingual' to refer to an environment marked by 'linguistic heterogeneity' (p. 214) where for a variety of reasons English rapidly became the medium of instruction in primary schools in Kenya. This parallels similar developments in other countries where English has become the preferred and dominant language, such as India, Singapore and South Africa (Hornberger \& Vaish, 2008). In many countries in Africa the dominance of English is a legacy of colonialism which continues to influence the implementation of multilingual education policies (Mazrui \& Mazrui, 1992; Rassool \& Edwards, 2010) and affects language learning, language use and language choice in bilingual and multilingual communities, schools and classrooms, such as those in Kenya.

For learners in multilingual primary schools early intervention in English language acquisition provides not only an extra language for communication, but also represents a vital tool for achieving academic goals and subsequent social mobility. According to Wray (2006) in order to establish strategies for successful performance in such target-language detached circumstances, the development of productive L2 teaching and learning 
initiatives needs to operate alongside a sound understanding of language learning processes.

This article offers an insight into language learning processes in an urban multilingual primary school in Kenya and highlights the language manoeuvres of teachers and learners in establishing strategies for successful performance in English. The data reveal the challenges posed by the context and environment, and the strategies and efforts of grade [Standard] 6 learners and their teachers in working towards successful L2 learning.

\section{Language Policy and Practice in Kenyan Schools}

The need for English and its importance in schooling in Kenya is enshrined in the National Educational Objectives, as postulated in the National Language Policy (Muthwii, 2004; Nabea, 2009). Apart from being taught as a subject in the curriculum, English is the Language of Instruction (LOI) for all other subjects (apart from Kiswahili). Kiswahili is the country's national language and is taught alongside English as a mandatory subject. The structure of primary schools is divided into two main sections and language use is 'on paper', structured in favour of multilingualism. In lower primary school (Standard 1-3), the use of Mother Tongue (MT) is allowed for reinforcing instruction in English-taught and examined subjects (Sure \& Ogechi, 2009). However, very little if any of this phenomenon actually exists in practice as pressure arising from the need to understand English for competitive academic pursuit has led to the demise of first-language instruction in schools. In addition, it is acknowledged that parents are increasingly showing positive attitudes towards learning English (Kioko \& Muthwii, 2004).

In upper classes (Standard 4-8), English is the official language of instruction. All school and national examinations are taken in English. The national examinations are the sole determinants of a learner's progression in education (Nabea, 2009) and this makes understanding of English a 'life-line' for all students regardless of their age or learning level.

Underpinning these three levels of languages [English, Kiswahili and Mother Tongue] is a controversy as to which should prevail in schools and at what levels (Nabea, 2009). Nabea argues that the inheritance of language policy from the colonial past stands up to 'contestation and mediation' by the masses, and suggests that so far a coherent decision has not been reached. Although schools are platforms from which language issues can be resolved and aligned, the multilingual nature of Kenya has remained a block towards the realisation of a comprehensive language policy in the school system (Kiarie, 2004; Kioko \& Muthwii, 2001).

\subsection{The Language Background of Learners}

Pupils in Kenyan schools can be said to be multilingual. Multilingual individuals speak or have knowledge of more than two languages in their communicative patterns (Miller, 2003; Cook, 2001). This situation is relatable to bilingualism where an individual has 'ability to communicate in two languages alternately' (Carter \& Nunan, 2004, p. 93).

In Kenya, most learners join school as bilinguals, speaking their first language (Mother Tongue) and Kiswahili. In other circumstances, a learner may understand two different first languages as a result of cross-linguistic migration or intermarriage (Cook, 2001; Muthwii, 2004) and still be a Kiswahili speaker. There are also those who join school with knowledge of Kiswahili as their first language (mainly from cosmopolitan urban settings) and may have some 'level' of English learnt from the home environment. These learners are taught English and Kiswahili at school. They can therefore be seen as both compound bilinguals (where learning of two languages takes place at school) and coordinate multilinguals, where different languages are learnt in different settings (Appel \& Muysken, 1988, p. 76).

\subsection{The State of English in Primary Schools}

Research into the level of English language proficiency in Kenyan primary schools has revealed significant levels of underperformance (Sure \& Ogechi, 2009; Kioko \& Muthwii, 2001). This may be a consequence of the many language identities and alternatives embedded within the day-to-day communicative functions of the learner, as well as the existence of environmental challenges (Hurley, 2003). Having at least two languages by the time they join school, learners may find introduction to learning and using English language as an 'intrusion' into their established system of communication (Sure \& Ogechi, 2009). According to Quality Education for Social Transformation (QUEST, 2007) and Muthwii (2004) learners are faced with English literacy challenges from the onset of their schooling. They are introduced to the art of listening, speaking, reading and writing through first language in an English-dominated curriculum. Muthwii (2004) argues that teachers and learners are left sorting out the conflicts between at least three languages and that learning English language against such conflicting backgrounds presents a 'tremendous' burden. Fundamentally, learners are required to use MT, Kiswahili and English in 'timetable-full' schedules of learning. Language confusion can result from traumatic 
change-overs during instructional sessions, and learners are frequently caught in the centre of this mix-up (QUEST, 2007; Muthwii, 2004).

Educational initiatives by QUEST (2007) to encourage mastery of English language in primary schools in Kenya reflect clear indications of English language underperformance in primary schools. Research carried out by QUEST (2007) revealed a dire need for an upgrading of the level of English literacy. Given that English is both the language of instruction (LOI) and the language of examination (LOE) in Kenya, this group aims to support the improvement of literacy by:

i) Developing English literacy norms to aid progress at different levels in primary schools;

ii) Providing affordable reading materials;

iii) Developing and experimenting with innovative ways to promote the reading culture in primary schools.

This policy and research background provides the context for our study and in Section 3, we discuss our choice of school (the case) and the methods used in our investigation.

\section{Methodology}

A primary school located in a multilingual urban setting in the Nakura area, Rift Valley Province in Kenya, was chosen as the case. Our rationale for selecting this school was based on our aim to capture the circumstances and conditions of the typical situation (Ellis, 1990) and the school presented a case with ten different spoken languages and comparable significant features in relation to other primary schools (Bell, 2005), in terms of staffing and ethnic origin of pupils and teachers. An additional reason was that one of the researchers (an ESL primary school teacher from Kenya) had professional links with the school and so could facilitate access to the research site.

Creswell (2007) argues that judging the merit of a case study requires the establishment of details that are sufficient and appropriate for others to judge the analysis in the context of the setting. We choose a single case in a multilingual setting to obtain an in-depth insight into the challenges of teaching and learning English, with the knowledge that studying multiple cases may not allow for the rich holistic analysis we wished to obtain. The case is bounded by time (4 weeks) and place (one school) and the respondents cut across the school population. Data were gathered through a multi-method approach, using questionnaires and follow-up semi-structured interviews with teachers, $(\mathrm{n}=20)$ and learner diaries with a sample of Grade [standard] 6 pupils $(\mathrm{n}=10)$. Thus by triangulating evidence from teachers and pupils we aimed to provide an in-depth analysis of the case we set out to study and synthesise successful language learning strategies.

\subsection{Data Collection Tools}

Questionnaires were chosen as the main tool for data collection with teachers due to the distance between the researchers in the UK and the teachers in Kenya, who were both respondents and the conduits for accessing data from pupils. The questionnaire design incorporated both closed and open-ended questions, with closed ended items placed on a four point Likert scale, (Oppenheim, 2000). The scaling and the four-point system were designed to give respondents a choice, e.g., 'agree' or 'disagree' but also to ensure that a response to every item was elicited, whilst open-ended elements provided space for participants to express more freely their opinions on the issue under study (Creswell, 2007; Davies, 2007).

Further open responses from teachers were obtained through follow-up semi-structured telephone interviews, a resourceful method which saves time and expense when researchers do not have direct access to the participants of the study (Creswell, 2007, p. 133). Although this method did not allow for full capture of non-verbal aspects of communication as in face-to-face interviews, it did allow us to interpret feelings and attitudes through respondents' voice variation and interjections (Bell, 2005). Through this method, a number of issues that had not been captured in the questionnaires emerged (Creswell, 2007) hence providing additional data and triangulation of evidence.

Data from learners came from Grade [standard] 6 pupils who were asked to note in their learner diaries, the English language learning strategies they used on a daily basis. We saw pupils' participation in the study as a means of capturing successful L2 language learning strategies by encouraging reflection on the activities they undertook every day (Blaxter, Hughes \& Tight, 2006), including those planned for them by their teachers. The diary entries also provided an indication of a learner's personal commitment to learning English.

Diaries were structured in a simple table format to enable pupils to directly note the activity/strategy and to encourage self-expression (Oppenheim, 2000). Ten guiding questions were developed and used to encourage reflection by learners on their language learning strategies. Each question was allocated a page in the diary and 
two columns were suggested for every page, that is, date and activity/strategy as shown in Figure 1.

Question: What did you do to remember the new words you learnt today?

\begin{tabular}{|l|l|}
\hline DATE & ACTIVITY/STRATEGY \\
\hline & \\
& \\
\hline
\end{tabular}

Figure 1. Learner diary format

The procedure for data gathering using learner diaries involved the whole class in two stages over a 4-week period. For the first 2 weeks, ten learners with higher levels of proficiency in English were asked to write their individual language learning strategies in notebooks. In weeks 3 and 4, five learners from this group were appointed as group leaders over the other classmates, and were asked to identify the different strategies they used as group members to improve their English language. They noted down the strategies they used in different language skill areas, such as speaking, reading, vocabulary and creative writing.

\section{Findings}

The findings reveal the numerous challenges encountered by ESL teachers and learners within the multilingual environment of Kenya. Questionnaires completed by the sample of 20 teachers show significant agreement about the challenging issues, shown in Figure 2. Follow-up interview discussions with teachers from the sample group further confirmed the prominence of these concerns.

\begin{tabular}{|c|c|c|c|c|}
\hline \multirow{2}{*}{$\begin{array}{l}\text { Challenges } \\
\text { Issue of concern }\end{array}$} & \multicolumn{4}{|c|}{ Respondents'opinions } \\
\hline & $\begin{array}{l}\text { Strongly } \\
\text { Agree }\end{array}$ & Agree & Disagree & $\begin{array}{l}\text { Strongly } \\
\text { Disagree }\end{array}$ \\
\hline School language policy is not fully reinforced & 5 & 8 & 7 & - \\
\hline $\begin{array}{l}\text { Most learners commonly use mother tongue in school thus } \\
\text { affecting learning of English }\end{array}$ & 8 & 7 & 5 & - \\
\hline $\begin{array}{l}\text { Learners have no difficulties in expressing themselves using } \\
\text { English }\end{array}$ & - & - & 8 & 12 \\
\hline $\begin{array}{l}\text { Mixing of languages by teachers/learners during English } \\
\text { lessons does not facilitate learning of English }\end{array}$ & 10 & 6 & 2 & 2 \\
\hline $\begin{array}{l}\text { Local English varieties are more common as opposed to } \\
\text { Standard English }\end{array}$ & 9 & 8 & 2 & 1 \\
\hline $\begin{array}{l}\text { Simultaneous teaching of English and Kiswahili has no effect } \\
\text { on learning English }\end{array}$ & 2 & 3 & 7 & 8 \\
\hline $\begin{array}{l}\text { Teachers come from college well prepared to teach English at } \\
\text { all levels in primary school }\end{array}$ & 4 & 8 & 6 & 2 \\
\hline Home support for English language learning is available & 1 & 2 & 7 & 10 \\
\hline $\begin{array}{l}\text { Pressure from curriculum demands to meet targets inhibits } \\
\text { creative and innovative language teaching }\end{array}$ & 11 & 6 & 3 & - \\
\hline $\begin{array}{l}\text { Pupils have difficulties with English sounds that are not } \\
\text { found in their mother tongue }\end{array}$ & 9 & 9 & 2 & - \\
\hline
\end{tabular}

Figure 2. Teachers' opinions of challenges for teaching and learning ESL

As Figure 2 shows one of the major challenges is that school language policy is not fully reinforced as $65 \%$ of respondents asserted agreement or strong agreement with this statement. The majority of teachers $(85 \%)$ also agreed that most learners use Mother Tongue in school thus affecting the learning of English, with nearly all respondents agreeing that learners had difficulties expressing themselves using English. Reinforcing this observation, in the telephone interviews a male teacher commented that learners have other youthful languages 
that 'make their spoken English even worse...' He gave the following example of a learner's use of youthful patois:

Yesterday nilim-show samoingine, akani-show hajali (English and Kiswahili in corrupted forms)

I showed him/her something yesterday, but s/he did not care (English)

This example of language use can be interpreted as a means of learners resorting to L1 when they fall short of the 'appropriate words' in attempting to convey their ideas (Smith, 1999), but may be a case of learners fitting into a 'peer language culture' rather than inadequacy in linguistic repertoire. Thus, the example shows the significance of language choice due to the social context of language learning rather than only being a learning strategy due to lack of linguistic knowledge in the target language.

The mixing and use of different languages in the language learning environment poses another major challenge for teaching and learning ESL. Most respondents (80\%) feel that mixing of languages during lessons does not facilitate learning of English and neither does simultaneous learning of English and Kiswahili (75\%). The teachers identified the following examples of code-mixing and switching between languages amongst their pupils:

Phonological interchanges, for instance:

$$
\begin{aligned}
& \text { Sound }[1] \text { for }[\mathrm{r}] \ldots \ldots \ldots \ldots . . . \text { (led/red) } \\
& \text { Sound }[\mathrm{t}] \text { for }[\mathrm{d}] \ldots \ldots \ldots \ldots \ldots . . \text { (town/down) }
\end{aligned}
$$

Transferring of forms from one language to English, e.g., a Kikuyu language proverb lifted to English:

Yumbukaga na kiria imeretie (Kikuyu)

It flies with what it has swallowed (English translation)

Code-mixing (mixing Kiswahili and English)

Tuna-come shule Saturday (We are coming to school on Saturday)

Hatuna permission (We have no permission)

She showed me madharau (She was spiteful)

Teachers said that learners encountered difficulties in using language within different contexts. As L2 discourse requires an attachment to actual social-cultural context to achieve its communicative purpose, (Carter \& Nunan, 2004) pupils may be reluctant to use English for communication, finding it too demanding to struggle with L2 when L1 is easily and spontaneously accessible. Furthermore, as local English language variations are more prevalent in school than the standard version and teachers may not be well prepared by their college training for teaching English across all levels in a primary school, as well as prone to use English language varieties that are regarded as 'errors or deviances' (Kioko \& Muthwii, 2001, p. 206), the school environment for learning Standard English is extremely challenging.

Learners' home background further affects the learning of English, as teachers reported that many families in Kenya 'had no knowledge of the subject...' This finding supports Nabea's (2009) observation that only $25 \%$ of the Kenyan population is literate in English. In the open-item questionnaire responses and follow-up interviews, teachers highlight three other major challenges to teaching and learning ESL: lack of a joint commitment towards teaching English; teacher shortages in primary schools and pupils' negative attitudes towards learning English. These concerns are illustrated through a selection of comments from the respondents given below:

English is only reinforced by the English teachers, but the medium of communication outside the class is Kiswahili and Mother Tongue... (ESL teacher)

Such a situation is seen by Wray (2006) as a 'contrary notion' of some subject-teachers viewing teaching and reinforcing of English during their subject's instruction as a risk, potentially sacrificing learning in their specific subject to the needs of English. However, the reluctance could be a result of curriculum pressure to meet the demands of a non-compromising syllabus that compels teachers to use any available 'medium' to 'push' the curriculum content towards completion. Noting this pressure, one respondent writes, 'there is syllabus pressure... not enough time... only 35 minutes to practice English...' and a teacher of Science in one class and English in another class, comments in her interview:

We have to teach thinking of exams... examination tactics... there is no time... teachers do a lot of work... what time do you teach it [English], and what time do you complete the science syllabus... (Science and English teacher) 
These pressures lead most schools to adopt a functional skills approach to language learning due to the rigid examination system that requires mainly reading and writing skills. This approach gives pupils technical skills in vocabulary, grammar and composition but fails to provide the necessary opportunities to use language in logic, critical thinking, and speech communication (Muthwii, 2004).

An examination orientated educational system and a literacy focused ESL curriculum is further pressured by a shortage of English teachers in primary schools. The largest number of teachers in the sample (95\%) noted the shortage of English teachers in primary schools and the strain on being able to provide quality language work for learners. One teacher comments, 'I cannot afford to give individual attention to pupils due to class workload and time factor'. Furthermore, $50 \%$ of the teacher-respondents observed that some pupils have negative attitudes towards learning English. One teacher comments 'some have negative attitudes towards learning English... pupils easily forget what they are taught... they seem to have poor memory...'. A teacher with 15 years' experience of teaching says 'learners lack interest towards English... they lack enough motivation...' and another teacher reflects that 'learners show unwillingness to use English in their day-to-day activities...' Attitudes towards language are significant factors in successful language learning (Edwards, 1994) and thus learners' negative attitudes pose additional barriers for teachers to tackle in their strategies for teaching and learning English in this complex multilingual environment. The next section presents the instructional approaches used by teachers to meet these challenges.

\subsection{Instructional Approaches Used by Teachers to Encourage Learning of English}

From the completed questionnaires, it is evident that teachers adopt different instructional approaches towards the teaching and learning of English. Figure 3 shows the approaches used by different teachers, the frequency of use for each approach, and the number of teachers that use each in their practice.

\begin{tabular}{|c|c|c|c|c|c|}
\hline Language Instructional approaches & Always & Frequently & Sometimes & Rarely & Not Used \\
\hline Learning by word \& doing (Total Physical Response) & 5 & 1 & 7 & 5 & 1 \\
\hline Group work/co-operative tasks & - & 4 & 13 & 2 & 1 \\
\hline Peer support or mentoring & 2 & 4 & 8 & 4 & 2 \\
\hline Multi-media approaches & - & - & 5 & 6 & 9 \\
\hline $\begin{array}{l}\text { Teaching writing skills (planning, organising own } \\
\text { work) }\end{array}$ & 5 & 5 & 4 & 4 & 2 \\
\hline Teaching language learning strategies & 2 & 8 & 6 & 3 & 1 \\
\hline Giving English language home work & 9 & 7 & 3 & 1 & - \\
\hline Allowing for learners own language learning initiatives & - & 2 & 5 & 8 & 5 \\
\hline Teaching from the situational context & 3 & 6 & 7 & 3 & 1 \\
\hline $\begin{array}{l}\text { Teaching and reinforcing good English use in all } \\
\text { curriculum subjects }\end{array}$ & - & 6 & 9 & 4 & 1 \\
\hline
\end{tabular}

Figure 3. Instructional approaches and number of teachers using them in the school

The results displayed in Figure 3 show that the Total Physical Response (TPR) approach is used by most teachers, with only $30 \%$ rarely/never using it. This approach is based on enabling language learning by verbal rehearsals and repetition (Oxford, 1990). Additionally, group work tasks are used 'sometimes' and peer support strategies are also adopted. Essentially, structured peer activities create opportunities for pupils to improve each other's language performance, offering learners intimate settings in which to negotiate the language they hear free from the 'stress and rapid pace of the teacher-fronted classroom' (Rulon \& McCreary, 1986 in McCafferty et al., 2006, p. 19).

A large percentage of respondents $(70 \%)$ teach writing skills as well as ensuring that learners have English language homework. Emphasis on writing skills is common in Kenyan schools (Muthwii, 2004). A small number of teachers indicated that they are not keen on homework and teaching writing skills.

A considerable majority of respondents teach learners how to use English learning strategies, only $20 \%$ of teachers in the sample group downplay this approach. Language learning strategies attempt to develop linguistic 
competence in the second/target language through use of deliberate acquisition attempts. According to Chamot and O'Malley, (1990, p. 43), use of such strategies promote use of the target language efficiently and clearly, and encourage a degree of 'automaticity in production.' Richards and Lockhart (1996) affirm that language learning strategies determine, to a great extent, the success level of learners in L2, arguing that absence of appropriate strategies results in language under-achievement.

The data show that $45 \%$ of the teachers in the sample use situational contexts to teach English, whilst $35 \%$ sometimes apply it and 20\% are not keen on this approach. Cook (2001) and Pitt (2005) emphasise the role of situational attachment to language learning which is seen as a way of helping learners to make sense of the language elements learnt. The teachers in the sample do not give much attention to learner autonomy in language learning as only $35 \%$ had tried it with their pupils. This practice contradicts advice given by Lodewyk et al. (2009) who believe that self- regulated learning can contribute to motivation, with pupils more engaged in a task if they have the feeling of owning that task. This suggests that teachers should provide choice to their learners whenever choice is available.

The teachers' responses reveal that the multi-media approach is not popular as only a small number use this with their pupils. The majority of teachers rarely or never use this approach. Verhoeven et al., (2009), argue that multi-media approaches provide interactive knowledge construction through stimulating learning environments for meaningful 'social and strategic learning processes', however this approach is not common in the case study school.

The data presented in the above section relate mainly to the closed items on the questionnaire. Teachers' responses to open questions and interviews reveal other strategies, which are discussed below.

\subsection{Other Strategies Used by ESL Teachers to Promote Learning of English}

Some teachers use the strategy of being friendly to learners to encourage pupils to seek assistance in case of language difficulties, for example in an interview a teacher says:

Sometimes I sit in class with my pupils during break time... some bring me self-initiated compositions... others recite me a poem... others sing an English song... I just listen and comment positively... showing much interest.

According to Dornyei (2008) and Rivers (1992) the way in which the teacher responds to pupils' concerns contributes significantly towards L2 learning, for example by reacting in an empathic manner, with mutual trust, respect and dependability. There is therefore a need to cultivate relationships which promote a warm language-learning atmosphere and which initiate positive classroom interaction. The teachers in the case study school report use of a diverse range of interactive activities such as storytelling, riddles, language-oriented word games, jokes and fun, magazines, all with the aim of creating more room for self and group expression. For example, one teacher said, 'I provide interesting and curiosity-arousing reading materials like magazines to my pupils.'

These elements can be effective ways of motivating, captivating interest and building learners' confidence in the use of English. Cary (2000) identifies the role of the teacher as a talk initiator in the classroom; for example, the teacher increases talk time for learners by generating opportunities for creative talk, reducing teacher talk, and incorporating learners' personal interests when encouraging English speaking. Rivers (1992) sees classroom interaction amongst pupils as allowing for and promoting emotional awareness, that is, 'the impulse to guard learners from hurt, fear of ridicule from peers' in order to enable a relaxed atmosphere where learning can be shared.

Teachers also write positive comments on learners' exercise books and verbally reinforce good language responses as part of their instruction. Sometimes they display exemplary pupils' work on school interactive boards. The aim is to help build learner's self-esteem and overall morale towards English as a subject. Employing effective strategies to improve motivation to learn is not only about providing rewards for achievement for pupils but also about 'fostering a set of cognitions that predispose them to be motivated to learn' (Jarvis, 2005, p. 119).

Teachers in the research sample also use whole school initiatives and policies such as demanding that pupils use only English at school, which can followed by a punishment if not adhered to. Although such corporate initiatives may have counter effects as some pupils may come to associate learning English with punishment resulting in strengthening negative attitudes towards the language, this practice is viewed by teachers as a means to enhance and promote exposure to English. They articulate to learners the benefits of practicing and using English as an essential tool for academic success, rather than viewing English as 'a language of suppressing' 
pupils' own established communication systems. Other strategies used by the school to promote good use of English language include the establishment of school clubs, such as a debating club, composition writing competitions and the encouragement of all subject teachers to use proper English when teaching their subjects.

The strategies used by teachers to tackle the challenges posed by the complex language-learning environment in Kenya provide only part of our analysis of learning English in the selected school. The strategies used by learners to improve their English language competence revealed through the learner diaries are discussed in the following section.

\subsection{Learners' Language Learning Strategies}

The data show that learners adopt different strategies to facilitate learning and improve their English. Although they may not be conscious of using 'strategies', the study shows that they are involved in activities which are in fact language learning strategies. Strategies can be seen as thoughts and behaviours that a learner/teacher engages in during language instruction, that are intended to influence a learner's encoding process ( $\mathrm{O}^{\prime}$ Malley \& Chamot, 1990, p. 17). They are the 'moment-by-moment techniques' employed to solve problems resulting from L2 input and output (Brown, 2000, p. 122). The use of strategies is seen as a way to overcome language-learning challenges where the need for language proficiency is vital. Learners may thus, consciously or unconsciously, use strategies in their effort to learn English (Wenden \& Rubin, 1991). The strategies used by pupils in our study can be categorised as individual level strategies such as, comprehension tactics, keeping vocabulary notebooks and using dictionaries and group level strategies which include working in groups, peer teaching, role-play, group translations and group word games. Examples of these strategies with illustrative comments in the learner's own voices are presented below.

\subsubsection{Individual Level Learner Strategies}

The strategies reported by pupils in the study reflect both common strategies and individual differences in approaches to language learning. Most pupils read comprehension passages 'first' then answer questions later. However, three pupils approach it differently. One boy said, 'I read the questions first then I read the [story] to find answers.' A girl said, 'After reading all the questions, I go back and read the story, and then I start to answer the questions...' and another girl 'I read questions before I read passage... when I read the passage, I see where answers are.'

All the learners participating in the study kept a vocabulary notebook where they wrote all the new words they learnt in and out of class. For example, one girl said 'After reading a storybook, I pick the new words and write them down in my vocabulary book.' A considerable number of learners (50\%) use dictionaries to find meanings of new words. They sometimes 'pick' words from the reading 'passages' then search for meaning from the dictionaries. Additionally, $80 \%$ use dictionaries and textbooks to check/confirm correct spellings after doing word/sentence dictations with peers. Other strategies involve seeking help from others in school and at home and individual practice and reinforcement activities, noted as follows by pupils in their diaries:

I take my friend's composition book to read her nice compositions

I write some work and ask my father to mark for me at home

I practice saying the poems we were taught because 'practice makes perfect'

I join debate club to improve my English

I write a lot of compositions to practice punctuations

I practice with words in making sentences at home

I do corrections carefully to see my mistakes

I ask for help from Standard 8 pupils who are good at English

According to Grainger (2004, p. 17) peer assistance can be extended to senior pupils in senior classes. Thus, learners from senior classes help those in lower classes in different language elements. This helps to develop both sets of learners as the senior feel responsible and 'able' to uplift the younger, while the younger in turn gets 'individualised' attention from their elder school 'siblings'.

\subsubsection{Group Level Learner Strategies}

Pupils highlighted ways in which they perform activities in groups both in and outside class to remember what they had learnt in class. Many of these activities are initiated by pupils as learners rather than planned for them by teachers. They include peer teaching, whereby one member of the group stands in front of the rest [as a teacher] as they practice 'sentence patterns' on the chalk board and role-plays which one group of learners noted 
in their group learner diary as follows:

During our free time, we acted the story our teacher narrated in class. Two of us were parents, others children, aunt and villagers. This helped us to remember the story. We also make jokes using English language for enjoyment. (Extract from a learner diary)

Other practices noted by pupils as supporting their language learning involve exchanging composition books after the teacher had marked and corrected their work. They wrote, 'We read each other's story then discuss the different ideas from each book.' Another group noted the use of translation as a strategy for learning English in the following way 'We discussed the Kiswahili work as a group, trying to get the correct words to translate the work from Kiswahili to English...' The use of peers to support language learning is generally a strong and positive aspect of strategies noted by learners but as the following example shows peers can also cause embarrassment:

We formed words using '-ness.' I started telling my friends how to use '-ness'. When I noticed I had said some words wrongly, I stopped and corrected myself. When I stopped, my friends started laughing at me, I felt shy... (Extract from a learner diary).

The other major set of activities learners use to support their language learning are word games. The majority of learners participate in group word-games. One group uses rope skipping to 'recite' new words. A girl describes this as, 'We like skipping at break time as we say the new words we learnt in the week; we say any word we can remember...' O'Malley and Chamot (1990) term these strategies as 'heterogeneous student teams' working together to solve language problems. Other statements from learner diaries on language learning activities with peers are:

I sat with my friend in the field doing spelling of words... my friend says a word, and then I spell it.

We do word and sentence dictations in class

I asked my friend to show me how to write plurals of nouns ending with -y

We collected things in the field with my friend and started describing them using the correct order of adjectives as taught by the teacher.

We read a passage with my friend and looked for the main points together.

The evidence presented above shows that learners have developed a range of strategies that they use to improve their English language production and proficiency in a complex and challenging multilingual environment. The use of learner diaries has captured strategies which are not part of the planned curriculum and the data show the autonomy and inventiveness of pupils in finding their own individual and group based strategies to support L2 learning.

\section{Conclusion}

This article has highlighted and discussed the challenges and strategies for teaching and learning English within a primary education environment in Kenya through a school-based study involving teachers and pupils. Both the approach used for the research and the findings based on data collected from teachers and young learners provide tools for developing successful L2 strategies for other multilingual settings. The findings show the complex and diverse challenges for teaching and learning English in a multilingual primary school. The policy context in Kenya contributes to the challenges faced by teachers as a conflicting and un-enforced school language policy leads to pupils who seem to prefer using Mother Tongue and Kiswahili to English at school. Mixing and use of different languages, code-switching and emerging use of patois by some children adds to the diversity of the language environment and to the complexity of the challenges faced by teachers of ESL. Furthermore, there remains a prevalence of English language varieties as opposed to the standard version, as noted in an earlier study by Kioko and Muthwii (2001). Moreover, an examination-oriented educational system leads to instructional pressure and literacy focused learning of English leaving little space for creative and innovative communicative language learning opportunities. This is compounded by teacher shortages in primary schools, teachers not feeling fully prepared for teaching English at all levels by their college training courses and little or no literacy boost for pupils from their home environments.

These challenges may suggest that the teaching and learning of English in the case study school is languid but the data actually show the tremendous efforts and activities of both teachers and learners in finding successful strategies for L2 learning. At classroom level, individual teachers use varied instructional approaches, shown in Figure 3, and nurture learning by creating a warm classroom climate where learners feel psychologically comfortable and are prepared to take risks in language learning and ask for assistance from their teachers outside 
the formal lesson time. As Figure 3 shows the only instructional approach that is little used in the school is multi-media approaches; this may be due to lack of multi-media resources or lack of training in using this approach to L2 learning. At school policy level, teachers try to reinforce directives on language use across the curriculum and though there are differing views on requiring pupils to use only English for communication in a multilingual school environment most teachers in this study view this as a successful ESL learning strategy and try to convince pupils of the benefits of the policy.

Pupils are equally active in developing successful language learning strategies and the use of learner diaries in this study has deserved two purposes. Firstly, completed diaries have provided data on learners' strategies that involve the use of minimal teaching resources and which can support ESL learning at primary school level in other multilingual environments. Secondly, and perhaps more importantly, the diaries have shown how they can serve as a tool for reflective language learning and promote motivation, autonomy and inventiveness amongst pupils and hence support their development as learners as well as their proficiency as language users. Pupils' individual level reinforcement strategies, such as keeping vocabulary notebooks, different comprehension tactics and seeking help from peers and elder schoolmates are easily transferable to other L2 contexts and group-level strategies, such as peer teaching, role- plays and group word games show how communicative language learning activities can be generated by pupils themselves by providing them with a process for reflective language learning.

\section{References}

Appel, R., \& Muysken, P. (1987). Language contact and bilingualism. London: Edward Arnold.

Asfaha, Y. M., \& Kroon, S. (2011). Multilingual education policy in practice: Classroom literacy instruction in different scripts in Eritrea. Compare: A Journal of Comparative and International Education, 41(2), 229-246. http://www.tandfonline.com/doi/pdf/10.1080/03057925.2011.547288

Bell, J. (2005). Doing your research project: A guide for first time researchers in education health and social sciences (4th ed.). London: Open University Press.

Blaxter, L., Hughes, C., \& Tight, M. (2006). How to research. Berkshire, UK: Open University Press.

Brown, D. H. (2000). Principles of language learning and teaching (4th ed.). Longman: San Francisco State University.

Carter, D., \& Nunan, D. (2004). The Cambridge guide to Teaching English to Speakers of Other Languages. Cambridge: CUP.

Cary, S. (2000). Second language learners: Answers to teachers' top ten questions. Portsmouth, NH: Heinemann.

Clegg, J., \& Afitska, O. (2011). Teaching and learning in two languages in African classrooms. Comparative Education, 47(1), 61-77. http://www.tandfonline.com/doi/pdf/10.1080/03050068.2011.541677

Cook, V. (2001). Second language learning and language teaching (3rd ed.). London: Oxford University Press.

Creswell, J. W. (2007). Qualitative inquiry and research design: Choosing among five approaches. London: Sage.

Davies, M. B. (2007). Doing a successful research project: Using qualitative or quantitative methods. New York: Palgrave Macmillan.

Dornyei, Z. (2008). Motivational strategies in the language classroom. New York: Cambridge University Press.

Edwards, J. (1994). Multilingualism. Middlesex: Routledge. http://dx.doi.org/10.4324/9780203430927

Ellis, R. (1990). Instructed second language acquisition. Oxford: Blackwell.

Gorman. T. P. (1968). Bilingualism in the educational system of Kenya. Comparative Education, 4(3), 213-221. http://www.tandfonline.com/doi/pdf/10.1080/0305006680040305

Grainger, T. (2004). Language and literacy. London: Routledge. http://dx.doi.org/10.1111/j.0034-0472.2004.03801011_2.x

Hornberger, N. H., \& Vaish, V. (2008). Multilingual language policy and school linguistic practice: Globalization and English-language teaching in India, Singapore, and South Africa. Compare: A Journal of Comparative Education, 395(3), 320. http://www.tandfonline.com/doi/pdf/10.1080/03057920802469663

Hurley, J. L. (2003). Meeting the needs of second language learners: An educator's guide. Alexandria: 
Association for Supervision and Curriculum Development.

Jarvis, M. (2005). The psychology of effective learning. Cheltenham: Nelson Thornes.

Kioko, A. N., \& Muthwii, J. M. (2004). English variety for the public domain in Kenya: Speaker's attitude and views. In A. Kioko, \& J. M. Muthwii (Eds.), New Language Bearings in Africa: A Fresh Quest. Clevedon, England: Multilingual Matters.

Kioko, A. N., \& Muthwii, J. M. (2001). Demands of a changing society: English inEducation in Kenya today. $\begin{array}{lllll}\text { Language, } \quad \text { Culture } & \text { Curriculum, 201-213. }\end{array}$ http://www.tandfonline.com/doi/pdf/10.1080/07908310108666622

Lodewyk, K. R., Winne, P. H., \& Jamieson-Noel, D. (2009). Implications of task structure on self-regulated $\begin{array}{lllll}\text { learning and achievement. Educational } & \text { Psychology, } & \text { 29, } & \text { 1-25. }\end{array}$ http://www.tandfonline.com/doi/pdf/10.1080/01443410802447023

Mazrui, A. M., \& Mazrui, A. A. (1992). Language in a multicultural context: The African experience. Language and Education, 6(2-4), 83-98. http://www.tandfonline.com/doi/pdf/10.1080/09500789209541330

McCafferty, S. G., Jacobs, G. M., \& DaSilvaIddings, A. C. (2006). Cooperative learning and second language teaching. Cambridge: Cambridge University Press.

Miller, J. (2003). Audible differences: ESL and social identity in schools. Clevedon, UK: Multilingual Matters.

Muthwii, M. (2004). Language planning and literacy in Kenya: Living with unresolved paradoxes. Current Issues in Language Planning, 34-50. http://www.tandfonline.com/doi/pdf/10.1080/14664200408669078

Nabea, W. (2009). Language policy in Kenya: Negotiation with Hegemony. Retrieved January 17, 2013, from http://www.jpanafrican.com/docs/vol3no1/3.1\%20Kenya\%20Language\%20Policy.pdf

O’Malley, J. M., \& Chamot, A. U. (1990). Learning strategies in second language acquisition. Cambridge: Cambridge University Press. http://dx.doi.org/10.1017/CBO9781139524490

Oppenheim, A. N. (2000). Questionnaire design, interviewing and attitude measurement (2nd ed.). London: Continuum.

Pitt, K. (2005). Debates in ESOL teaching and learning: Cultures, communities and classrooms. Oxon: Routledge. http://dx.doi.org/10.4324/9780203347089

Quality Education for Social Transformation - QUEST. (2007). Promoting English literacy and reading. QUESTAFRICA Policy Briefing. Retrieved January 17, 2013, from http://www.hsk.org.uk/docs/policybriefing.pdf

Rassool, N., \& Edwards, V. (2010). Multilingualism in African schools: Constraints and possibilities. Language and Education, 24(4), 277-281. http://www.tandfonline.com/doi/pdf/10.1080/09500781003678720

Richards J. C., \& Lockhart, C. (1996). Reflective teaching in second language classrooms. New York: Cambridge University Press.

Rivers, W. M. (1987). Interactive language teaching. Cambridge: Cambridge Press.

Smith, M. S. (1994). Second language learning: Theoretical foundations. London: Longman.

Sure. K., \& Ogechi, N. O. (2009). Linguistic human rights and language policy in the Kenyan education system. Cheltenham: Nelson Thornes.

Verhoeven, L., Paas, F., \& Schnotz, W. (2009). Cognitive load in interactive knowledge construction. Learning and Instruction, 19(5), 369-375. http://dx.doi.org/10.1016/j.learninstruc.2009.02.002

Wray, D. (2006). Teaching literacy across the primary curriculum. Exeter, UK: Language Matters. 